\title{
The role of microstructural development in the hydrothermal corrosion of cast and HIPed Stellite 6 analogues in simulated PWR conditions
}

\author{
G.N. Karimi a, M.J. Carrington ${ }^{\text {a }}$, J. Thomas ${ }^{\text {b }}$, P.H. Shipwaya ${ }^{a}$ D.A. Stewart ${ }^{c}$ and T. Hussain ${ }^{a}$ \\ a Faculty of Engineering, University of Nottingham, University Park, Nottingham, NG7 2RD, \\ UK \\ b School of Physics \& Astronomy, University of Nottingham, University Park, Nottingham, NG7 \\ 2RD, UK \\ ${ }^{c}$ Rolls-Royce plc, Derby, UK.
}

\section{Abstract}

The corrosion behaviour of cast and HIPed Stellite 6 analogue materials in PWR-simulating conditions was investigated. The cast alloy exhibited localised corrosion at the boundary between the matrix and the $\mathrm{M}_{7} \mathrm{C}_{3}$ carbides, with this being attributed to chromium depletion in the matrix associated with the carbide growth. In contrast, the HIPed alloy exhibited no localised corrosion. The carbon content of the cast Stellite 6 analogue was right at the top end of the range indicated in the Stellite 6 specification: this results in a high fraction of carbides and a general depletion of the chromium content of the matrix.

Keywords. Stellite 6, Corrosion behaviour, PWR conditions, chromium depletion, preferential oxidation.

\section{Introduction}

The primary circuit of a pressurised water reactor uses water as the heat transfer medium, with this typically operating at a temperature of around $300^{\circ} \mathrm{C}$. Boric acid, lithium hydroxide, 
and excess hydrogen/oxygen are commonly added to the coolant in a PWR in order to assist in reactivity control during operation and to keep impurity and corrosion conditions within acceptable limits. Although metal release rates are typically low, small amounts of corrosion product can be activated in the reactor core resulting in a radiation field increase in the coolant system [1]; this issue is particularly prevalent with cobalt-containing corrosion products due to the transmutation of cobalt-59 to the $y$-emitting isotope, cobalt- 60 .

Cobalt-based alloys have traditionally been used as hardfacing materials for components in nuclear pressurised water reactors (PWRs) such as valves, turbines and pumps since they exhibit high corrosion resistance and desirable tribological behaviour under sliding wear conditions [2]. The cobalt-based alloy Stellite $6^{\circledR}(\mathrm{Co}-29.0 \mathrm{Cr}-4.5 \mathrm{~W}-1.1 \mathrm{C}$ (wt. \%)) has been the workhorse for providing high levels of wear resistance and extended service lives in valve components installed in power generating facilities for over 75 years; for example, Stellite $6^{\circledR}$ is often used in seating faces to minimize wear and prevent both seizing and galling [3].

Stellite ${ }^{\circledR}$ alloys with a medium carbon content $(0.5-1.2$ wt.\%) are designed to combat corrosion or simultaneous corrosion and wear [4] with these properties not only being affected by the alloy composition, but by the microstructure, which itself is dependent upon the route of manufacture. The corrosion resistance of cast Stellite $6^{\circledR}$ (including weld overlay Stellite $6^{\circledR}$, which also exhibits a cast structure, albeit one which solidification is generally both more rapid and directional) is often limited by features such as grain boundary carbide precipitation, insufficient levels of chromium in the matrix following formation of both carbides and Laves phases, and by chemical segregation in both cast and weld overlay microstructures materials [5]. In contrast, HIPing of powder-formed Stellite $6^{\circledR}$ results in homogenous, fine-grained microstructures which are free of segregation and this often confers both superior tribological and corrosion properties [6,7], and thus is being employed more widely in the manufacture of components for service in aggressive environments which require this combination of properties [8, 9]. 
Crook and Meyer [10] conducted tests on cast UNS R30006 (which has a similar specification to Stellite $6^{\circledR}$ ) in oxidizing and non-oxidizing acid media to assess the influence of microstructure upon corrosion resistance, and concluded that segregation in the cast microstructure is detrimental to corrosion in those media that promote localized attack. More specifically, in studies on the corrosion behaviour of Stellite $6^{\circledR}$ in saline solutions, corrosion was observed to initiate and propagate at the interface between the matrix and carbide and it was suggested that this was due to there being a lower chromium concentration in the matrix at this interface $[11,12]$, associated with its segregation as the chromium-rich carbide is formed [13].

The corrosion behaviour of both wrought (cast, hot rolled and heat treated) Stellite $6^{\circledR}$ and HIPed Stellite $6^{\circledR}$ in $3 \% \mathrm{NaCl}$ at ambient temperature has been compared using electrochemical techniques by Mohamed et al. [14] who concluded that HIPing could potentially improve the localised crevice corrosion resistance and related their findings to the crevice corrosion models developed by Oldfield and Sutton [15]. It was argued that HIPing also improved the pitting corrosion resistance with this being attributed to the finer grain size combined with a fine and uniform distribution of carbides [14]. In various corrosion tests under a range of conditions $[11,12]$, HIPed Stellite $6^{\circledR}$ was observed to exhibit superior corrosion resistance when compared to cast Stellite $6^{\circledR}$, with this being attributed to a lack of segregation in the microstructure.

As well as the corrosion behaviour being of interest, Malayoglu and Neville [16] conducted a comparative study on the erosion-corrosion performance of both HIPed and investment cast Stellite $6^{\circledR}$ in $3.5 \% \mathrm{NaCl}$ solution as a function of temperature and the level of erosive particle loading. They found that in all cases, the HIPed Stellite $6^{\circledR}$ exhibited the higher erosioncorrosion resistance, which they attributed to the fact that the carbides are not interconnected in the HIPed material whereas eutectic and dendritic carbides in the cast structure form a network of interconnected material. Furthermore, the mean free path between carbides is much smaller in the HIPed material and as such the material responded homogenously to 
erosion-corrosion. Another study comparing the erosion-corrosion behaviour of a range of HIPed and weld-deposited Stellite alloys in a nitric acid environment demonstrated that the HIPed alloys generally exhibited a lower mass loss which was again attributed to the finer microstructure [17]. A similar conclusion was also reached by Neville and Malayoglu [18] who attributed the superior corrosion resistance of HIPed Stellite 6 to its microstructure with equiaxed carbides and an absence of areas of chromium-depleted matrix material, due to reduced segregation.

To allow generalisation in this paper, alloys with a composition based upon that of Stellite $6^{\circledR}$ (i.e. Stellite 6 analogues) will together be known as S-6 alloys. It is clear from the literature that the corrosion performance of an S-6 alloy is affected by its processing route, since it is this that governs the microstructural characteristics of the material. However, it is also recognised that the corrosion mechanisms of such alloys are highly dependent upon the corrosion conditions themselves. The corrosion conditions in the primary circuit of a PWR are very different to those generally reported in the literature (typically ambient conditions with a range of active species) $[19,20]$. To the author's knowledge, there are no reports in the literature in which the behaviour of cast and HIPed S-6 alloys in conditions relevant to their exposure in a PWR primary circuit exist, and as such, the aim of this present study is to investigate and explain the differences in the corrosion behaviour of HIPed and cast S-6 alloys in conditions simulating the primary circuit of a PWR, namely high temperature $\mathrm{pH}$-adjusted water.

\section{Experimental methodology}

\section{Materials}

Two commercially available S-6 alloys were the subject of this study, with one being cast and the other being formed by HIPing of powder. The cast S-6 alloy (Weartech 6 (WT-6 ${ }^{\circledR}$ ), Weartech International Ltd, Port Talbot, U.K.) was manufactured by sand casting. A bar of 30 $\mathrm{mm}$ diameter by $100 \mathrm{~mm}$ length was supplied by the manufacturer from which disc-shaped 
samples of $30 \mathrm{~mm}$ diameter by $3 \mathrm{~mm}$ thickness were machined. The HIPed S-6 alloy was sourced from LSN Diffusion Ltd (Ammanford, U.K) and was supplied in the form of discshaped samples of $30 \mathrm{~mm}$ diameter and $10 \mathrm{~mm}$ thickness. HIPing of the powders was conducted under their standard condition, namely $1200^{\circ} \mathrm{C}$ and $100 \mathrm{MPa}$ pressure for 4 hours [21]. Table 1 shows the chemical composition of the two alloys, both measured by AMG Superalloys UK Limited, Rotherham, U.K.).

Samples for corrosion testing were wet ground with silicon carbide abrasive papers down to 1200 grit, followed by polishing with $6 \mu \mathrm{m}$ and then $1 \mu \mathrm{m}$ diamond abrasives. To assist in identification of corrosion damage, there was a need to be able to examine the same areas of the sample before and after corrosion exposure, so that the manner in which different microstructural features behaved could be characterised; accordingly, a Vickers macrohardness indentation (with a $20 \mathrm{kgf}$ load) was used to mark the sample surface prior to the exposure in the autoclave to aid in locating the same regions before and after exposure.

\section{Autoclave corrosion testing}

To study the corrosion behaviour in conditions similar to the primary circuit of a PWR, a solution of lithiated water $(\mathrm{LiOH} 8.5 \mathrm{mg} / \mathrm{kg})$ with a $\mathrm{pH}_{20^{\circ} \mathrm{C}}$ of $\sim 10.5$ was prepared with approximately 1.2 litres of the solution being loaded into a 316 stainless steel autoclave. The test samples were placed on mesh shelves of a 316 stainless steel jig, and the jig was submerged in the solution in the autoclave. Following closure of the autoclave, air was purged out of the autoclave and the solution by bubbling of oxygen-free nitrogen into the solution at the bottom of the autoclave at $2 \mathrm{~L} \mathrm{~min}{ }^{-1}$ for 90 minutes, with venting at the top. After the deoxygenation process, an Orion Star A329 meter (Thermoscientific, Singapore) was used to measure both the $\mathrm{pH}$ and the rugged dissolved oxygen (RDO) content of a sample of the solution which was extracted from the autoclave. The autoclave was then sealed, and an electrical band heater was employed to heat up the autoclave to a temperature of $300^{\circ} \mathrm{C}$ (as measured via a thermocouple in a thermowell) which was maintained for the 30 days of the exposure. This length of exposure was selected based upon previous tests in that it allowed 
the development of corrosion to a level that facilitated its characterisation. After 30 days, the system was cooled down for 24 hours before the mesh jig with the samples was removed and the samples removed for analysis.

\section{Microstructural characterization}

Optical images of the microstructure of the samples before and after exposure were taken using a Nikon UFX optical microscope (Nikon UK Ltd, Kingston Upon Thames, U.K.). A JEOL 6490LV microscope was used for scanning electron microscopy (SEM) (using both secondary electron (SE) and backscattered electron (BSE) imaging) and for energy dispersive X-ray (EDX) analysis. An accelerating voltage of $20 \mathrm{kV}$ and a working distance of $10 \mathrm{~mm}$ was employed for all of the SEM characterization work.

X-ray diffraction was conducted on sample surfaces both before and after autoclave exposure using a Siemens D500 diffractometer (Dallas, Texas, USA) with $\mathrm{Cu} \mathrm{K}_{a}$ radiation. Peak identification was performed using EVA software (Bruker AXS Ltd., Coventry U.K.) using the PDF-database from the International Centre for Diffraction Data.

\section{Atomic force microscopy}

Atomic force microscopy (AFM) images were acquired using both amplitude modulated tapping (AC) mode and contact mode with an Asylum Research MFP-3D AFM (Santa Barbara, CA, USA). During contact mode electrical conductivity measurements, a bias of 6 - $10 \mathrm{~V}$ was maintained between the conductive probe tip (ElectriMulti75-G) and the sample with a 500 $M \Omega$ resistor being placed in series to limit the tip sample current. Current and topography maps of the sample surfaces were obtained simultaneously, enabling correlation between the topography and the electrical conductivity of features observed.

\section{Modelling of microstructural development}

The commercial software package Thermo-Calc (Version 2017b) with the SSOL-5, SGTE Alloy solutions database V5.0 [22] was used to assist in the understanding of the 
microstructures of both the cast and the HIPed S-6 alloys. For both alloys, the measured compositions of the alloys (Table 1) were used in the models.

For the cast S-6, a Scheil-Gulliver solidification simulation was used to model the solidification and microsegregation. Use of the Scheil-Gulliver approach to determine the solidification path is useful for practical casting modelling [23] and is often applied to estimate the extent of microsegregation during solidification [24] since, for non-equilibrium solidification processes occurring over typical microstructural length scales, it is seen to provide a better approximation of the solute segregation than does the equilibrium lever rule $[25,26]$. The Scheil-Gulliver model assumes no diffusion in solid phases except for carbon, which is assumed to achieve equilibrium partition; however, perfect mixing (theoretically infinite diffusivity) is assumed in any liquid phases.

Using its measured composition (Table 1), the phase composition of the HIPed S-6 at the HIPing temperature of $1200^{\circ} \mathrm{C}$ was also modelled using Thermo-Calc. In addition, in an attempt to understand the sensitivity of the chromium content of the cobalt-rich matrix phase to the carbon content of the alloy, the phase make-up of the alloy was modelled across the range of carbon contents allowable in the Stellite 6 alloy specification ( $0.9 \mathrm{wt} \%$ to $1.4 \mathrm{wt} \%)$; in this modelling, all other alloying elements were held at their measured values except for cobalt which was employed to balance the change in carbon content.

\section{Results}

\section{Microstructure and corrosion behaviour of the cast S-6 alloy}

The measured chemical composition of the cast S-6 is presented in Table 1, both in weight and atomic fractions. Figure 1 is a BSE-SEM image showing the hypoeutectic microstructure of the cast S-6 which consists of Co-rich metallic dendrites (grey), Cr-rich carbides (dark) and a small fraction of $\mathrm{W}$-rich carbides (bright). Various authors $[12,27,28]$ have reported similar microstructural features in cast Stellite $6^{\circledR}$ (or its analogues), whilst some [29] have identified 
instead that only two phases are observed in the microstructure of sand cast Stellite $6^{\circledR}$, with $\mathrm{M}_{7} \mathrm{C}_{3}$ carbides in the interdendritic regions of a Co-rich face-centred cubic matrix.

Table 2 presents the measured proportion of the metallic elements in the three phases identified in Figure 1; other elements (including carbon) are excluded from the analyses. The Co-rich matrix has a cobalt content of 60.3 at\% with chromium (26.3 at\%) as the major alloying element. The metal content of the Cr-rich carbide is dominated by chromium ( 83.4 at\%) with cobalt (12.9 at\%) as the major alloying element. In the W-rich carbides, the metallic sites were filled by chromium and cobalt in almost equal amounts ( 35 at\%), with tungsten and silicon also making up significant fractions (18.1 at\% and 8.9 at\% respectively).

Figure 2(a) is a BSE-SEM micrograph of the polished cast S-6 microstructure before autoclave exposure, with the box highlighting a region for which the AFM height map is presented in in Figure 2(b). By comparing the images in Figures 2(a) and 2(b), it can be seen that the polishing process has resulted in preferential removal of the softer matrix material, with the carbides (dark phase) in Figure 2(a) corresponding to the higher (brighter) regions the AFM image (Figure 2(b)). A profilometric line profile was taken across a representative carbide / matrix boundary region (its position indicated by the red line in Figure 2(b)) and is presented in Figure 3 (along with other equivalent profiles following autoclave exposure which will be described later in the paper). In this case, it can be seen that the carbide is standing proud of the matrix by around $20 \mathrm{~nm}$, with this height transition taking place over a distance of around $2 \mu \mathrm{m}$ (i.e. a slope of $\sim 1: 100$ in the transition between these two regions).

Figure 4 shows XRD patterns of the cast S-6 before and after autoclave exposure; given the coarse microstructure of the cast material, an attempt was made to eliminate effects of microstructural texture on the patterns by using the same sample placed in the same location (including orientation) in the diffractometer. Both patterns exhibit peaks associated with the two main phases, namely $\mathrm{Co} f c c$ and $\mathrm{Cr}_{7} \mathrm{C}_{3}$, confirming that the $\mathrm{Cr}$-rich carbide phase observed in Figure 1 has the $\mathrm{Cr}_{7} \mathrm{C}_{3}$ structure, as previously described [30]. Due to its small fraction in the microstructure, no evidence of the W-rich carbide was observed in the XRD 
pattern. No significant differences were observed in the XRD pattern following autoclave exposure (both in peak position and relative height) indicating that any corrosion product retained on the surface was either amorphous in nature or too thin to be a significant influence on the XRD pattern.

Micrographs of the cast S-6 both before and after autoclave exposure are presented in Figure 5(a) - (f). The images are presented in pairs, with the same regions being imaged before and after exposure at the same magnifications so that specific microstructural changes can be readily identified; Figures 5(a) - (d) are optical micrographs, whilst Figures 5(e) - (f) are BSESEM micrographs.

Following autoclave exposure, optical microscopy revealed regions with different colouration on the surface; these are interference colours associated with the corrosion product formed, and if it assumed that these are akin to the colours associated with heat tinting of stainless steels, the yellow / brown colour indicates a film thickness of up to $\sim 75 \mathrm{~nm}$, with the blue colouration being associated with thicker films, typically between $100-175 \mathrm{~nm}$ [31]. In correlating the colours with the microstructural features (Figures 5(a) and (b)), a brown colouration is observed on the dendritic regions of the Co-rich matrix whilst the blue colouration was observed in the regions with the Cr-rich carbide.

Higher magnification optical microscopy (Figures 5(c) and (d)) showed that the blue colouration (associated with a thicker corrosion film) was actually associated not with the carbide itself, but instead was associated with the regions of the Co-rich matrix close to the Cr-rich carbide, with the Cr-rich carbide and the bulk of the Co-rich matrix exhibiting a brown colouration, indicating preferential corrosion of the Co-rich matrix in regions close to a boundary with the Cr-rich carbide. Figures 5(e) and (f) are a BSE-SEM image pair of the cast S-6 microstructure before and after autoclave exposure, and were chosen so that a region where the W-rich carbides had formed was included; Figure 5(e) shows that a thin layer of the W-rich carbide has formed at the boundary between the Co-rich matrix and the Cr-rich carbide, although it is noted that not all of the boundary of this type is decorated in this way. 
Following autoclave exposure, a dark boundary layer is observed to have formed at the boundary between the Co-rich matrix and the Cr-rich carbide, but only in regions which were not decorated with the W-rich carbide. More specifically, the dark boundary layer was not observed either at the boundary between the Cr-rich carbide and the W-rich carbide or at the boundary between the W-rich carbide and the Co-rich matrix, except where the amount of Wrich carbide was very small, in which case engulfment was sometimes observed, an example of which is highlighted in Figure 5(f). Careful comparison between Figure 5(e) (before exposure) and Figure 5(f) (after exposure) indicates that the dark layer that has appeared after the autoclave exposure is formed from the Co-rich matrix rather than from the Cr-rich carbide; an example of an area where it is clear the it is the matrix which is corroding to form the dark boundary layer is highlighted in Figure 5(f).

Figure 6(a) is a BSE-SEM image of the region of the exposed sample highlighted in the optical image shown in Figure 5(d) with Figures 6(b)-(g) being the corresponding EDX maps of cobalt, chromium, iron, oxygen, silicon and tungsten The blue / white regions in the optical image (Figure 5(d)) can be clearly identified as the Co-rich matrix, with the BSE-SEM image in Figure 6(a) clearly revealing a dark boundary layer at some (but not all) of the interface between the Co-rich matrix and the Cr-rich carbide after exposure. The EDX maps show that there is no clear segregation of the metallic elements within either of the two phases themselves (although the preferential partition between the phases is clear and is in accord with the data presented in Table 2). The oxygen map in Figure 6(e) confirmed that the dark layer observed at the boundary between the Co-rich matrix and the Cr-rich carbide in Figure 6(a) was rich in oxygen.

A slightly reduced region of the area of the exposed cast S-6 investigated by EDX in Figure 6 was also investigated by AFM. The BSE, optical and AFM maps (both height and current) of this region are presented in Figures $7(a)$ to (d) respectively, with the correlation between features using the four techniques being readily observed. The cAFM contact mode height map indicates that, following exposure, the Cr-carbide region is still higher than the Co-rich 
matrix. To compare this quantitatively with the height map before exposure, a line profile was extracted from this map (see the red line in Figure $7(\mathrm{c})$ ) with this line profile being presented alongside one taken from the unexposed cast S-6 in Figure 3; here, it can be seen that following exposure, the height difference between the Cr-rich carbide and the Co-rich matrix is more than $60 \mathrm{~nm}$ (much greater than the equivalent height difference before exposure) indicating that the Co-rich matrix recedes faster than the Cr-rich carbide during exposure.

Conductive AFM (CAFM) was conducted with the map of the same area presented in Figure $7(d)$. In this map, the highest resistance (lowest current) following autoclave exposure is observed in the Co-rich matrix regions close to the Cr-rich carbide, with the current flow both in the Cr-rich carbide itself and in the Co-rich matrix further away from its boundary with the Cr-rich carbide being higher. This observation is in accord with the optical image of the same area presented in Figure $7(\mathrm{~b})$ and indicates that the high resistance is associated with the formation of a thicker oxide layer (which gives the blue / white interference colour) on the Corich matrix close to its boundary with the Cr-rich carbide.

\section{Microstructure and corrosion behaviour of the HIPed S-6 alloy}

The measured chemical composition of the HIPed S-6 is presented in Table 1, both in weight and atomic fractions. The HIPed S-6 has a significantly lower carbon content than the cast S6 (1.0 wt. \% compared to 1.5 wt. \%) along with significantly lower iron and nickel contents. A BSE-SEM micrograph of unexposed the HIPed S-6 is presented in Figure 8 which shows a Cr-rich carbide phase (dark) and a Co-rich matrix phase (grey). The Cr-rich carbides have a size range of 1 - $5 \mu \mathrm{m}$ and are uniformly distributed in the Co-rich matrix. The $\mathrm{W}$-rich carbide phase which was observed in the cast S-6 was not observed in the HIPed S-6.

Table 3 presents the proportion of metallic elements in the two phases identified in Figure 8; other elements (including carbon) are excluded from the analyses. The Co-rich matrix has chromium and iron contents of 25.2 at\% and 0.9 at\% respectively, notably less than the equivalent values for the Co-rich matrix of the cast S-6 (26.3 at\% and 3.2 at\% respectively see Table 2); in the case of the chromium content, this is unexpected given that the carbon 
content of the HIPed S-6 is significantly lower than that of the cast S-6 (increasing carbon results in chromium depletion of the matrix due to carbide formation) and may result from the EDX interaction volume being of the same scale as the microstructural features, with signal therefore coming from the carbides as well as the matrix. The composition of the Cr-rich carbide in the HIPed S-6 is very similar to that of the Cr-rich carbide observed in the cast S-6 (Table 2), with the metallic fraction being dominated by chromium with cobalt as the main secondary element.

Figure 9 shows the XRD patterns of the HIPed S-6 before and after autoclave exposure; as for the cast S-6, both patterns exhibit peaks associated with the two main phases, namely of Co fcc and $\mathrm{Cr}_{7} \mathrm{C}_{3}$, confirming that the Cr-rich carbide phase observed in Figure 8 has the $\mathrm{Cr}_{7} \mathrm{C}_{3}$ structure. Again, no significant differences were observed in the XRD pattern following autoclave exposure (both in peak position and relative height) indicating that any corrosion product retained on the surface was either amorphous in nature or too thin to be a significant influence on the XRD pattern.

As before, micrographs of the HIPed S-6 both before and after autoclave exposure are presented in Figures 10(a) - (d). The images are presented in pairs, with the same regions being imaged before and after exposure at the same magnifications so that specific microstructural changes can be identified. Comparing the optical micrographs in Figures 10(a) and (b) indicates a general brown-blue colouration of the sample surface as a result of the autoclave exposure; these images are at the same magnification as those presented for the cast S-6 in Figures 5(a) and (b), but due to the fine scale of the HIPed microstructure, the nature of corrosion across the different microstructural phases cannot be resolved optically in this case. Figures 10(c) and Figure 10(d) are BSE-SEM micrographs of the same region of HIPed S-6 before and after exposure. Figure 10(d) shows very little evidence of corrosion having taken place following autoclave exposure; specifically, no dark boundary layer between the Cr-rich carbide and Co matrix phases (as seen in the cast S-6 sample in Figure 5(f)) was observed. 
In the examination of the cast S-6 following autoclave exposure, AFM was conducted on a particular region that had already been examined by SEM; however, due to the fine scale of the microstructure, this correlation between SEM and AFM imaging was not possible for the HIPed S-6. Figure 11(a) is a high magnification optical micrograph of exposed HIPed S-6 where it can be seen that the colouration due to corrosion during exposure is less apparent on the carbides than it is on the matrix. AFM maps of the autoclave-exposed surface are presented in Figures 11(b) and (c); the cAFM tapping mode height map (Figure 11(b)) indicates that after exposure, the Cr-rich carbides were higher than the Co-rich matrix as previously observed for the cast S-6 after exposure; to compare these quantitatively, a line profile was extracted from this map (see the red line in Figure 11(b)) and this line profile is presented alongside that taken from the exposed cast S-6 in Figure 3; here, it can be seen that following exposure of the HIPed S-6, the height difference between the Cr-rich carbide and the Co-rich matrix is very similar to that observed in the cast S-6, namely around $60 \mathrm{~nm}$.

cAFM of the autoclave exposed HIPed S-6 is presented in Figure 11(c); as observed for the cast S-6, the carbide regions exhibit the highest current flow, indicating that these are not as effectively covered by a higher resistance corrosion product as the matrix phase. There are variations in the current flow in the matrix itself, with some evidence that the regions of lowest current flow are in the matrix close to the carbides.

\section{Microstructural development in the cast S-6 and HIPed S-6 alloys}

It is clear that the cast and HIPed S-6 materials are microstructurally different, and that they also exhibit very different corrosion behaviours. In seeking to understand these differences, it must be recognised that as well as being manufactured by very different processes, the two materials also have different compositions, and thus there is a need to understand the microstructural development in these two alloys in order to better understand the factors which control the corrosion behaviour.

During solidification of complex alloys such as S-6, dendritic and eutectic microstructures are often observed, with these resulting in substantial segregation of some alloying elements 
(such as chromium [32]) and resulting in cored structures across the dendrites. Figure 12 presents EDX data relating to the coring of a dendrite arm within the cast S- 6 structure, with Figure 12(a) indicating the location of an EDX linescan, and Figure 12(b) showing the measured concentrations of both chromium and silicon across the dendrite arm. The dendrite arm is around $30 \mu \mathrm{m}$ in width and is bounded on both sides by $\mathrm{M}_{7} \mathrm{C}_{3}$; close to these boundaries with the $\mathrm{M}_{7} \mathrm{C}_{3}$, depletion in chromium and enrichment in silicon was observed across the dendrite arm. Given that the carbides themselves are higher in chromium and poorer in silicon than the matrix, the respective depletion and enrichment in the dendrite arms in the regions up to around $5 \mu \mathrm{m}$ from the carbides cannot be attributed to EDX interaction volumes overlapping with the carbides themselves; indeed, given the interaction volumes, the actual depletion of chromium and enrichment of silicon in the C-rich matrix close to the Cr-rich carbide is expected to be much higher than indicated by the EDX data presented in Figure 12(b).

To understand the microstructural development in the cast S-6, Thermo-Calc was employed; Scheil-Gulliver solidification was employed to account for the microsegregation (coring) that is a consequence of the rejection of solutes by the solid into the interdendritic liquid [33] with carbon being retained as a fast-diffuser. The predicted mass fraction of solid as a function of temperature is shown in Figure 13(a) with indications of the temperatures that certain phases begin to form in the microstructure. At $1272^{\circ} \mathrm{C}$, the formation of both $\mathrm{Co} f c c$ and $\mathrm{M}_{7} \mathrm{C}_{3}$ begins and continues as the temperature continues to fall, with only $\sim 9 \mathrm{wt} . \%$ of the material predicted to remain as liquid by the time that the temperature had fallen to $1200^{\circ} \mathrm{C}$. Solidification continues as the temperature falls further, with the model predicting that $M_{12} C$ will begin to form from the liquid at around $984^{\circ} \mathrm{C}$. It is noted that although both $\mathrm{M}_{6} \mathrm{C}$ and $\mathrm{M}_{12} \mathrm{C}$ were allowed in the solidification model, the model did not predict formation of $\mathrm{M}_{6} \mathrm{C}$. The prediction of $\mathrm{M}_{12} \mathrm{C}$ as a minor phase is in accord with the micrograph presented in Figure 5(e) and with the identification of $\mathrm{M}_{12} \mathrm{C}$ in sand cast Stellite $6^{\circledR}$ by $\mathrm{Yu}$ et al [30]. For comparison, the equilibrium solidification of material with the cast S-6 composition was also modelled. In this case, in 
contrast to the Scheil-Gulliver solidification model, $\mathrm{Co}(\mathrm{fcc})$ and $\mathrm{M}_{7} \mathrm{C}_{3}$, are the only phases predicted to form upon solidification, with a carbide fraction of $15 \mathrm{wt} \%$ at the solidus temperature.

Figure 13(b) shows the predicted change in the composition of the cobalt-rich matrix formed at each temperature on cooling during Scheil-Gulliver solidification of the cast S-6. As can be seen, strong partition of both chromium and silicon are observed, with the first matrix to solidify (i.e. the centre of the dendrite arms) being enriched in chromium and depleted in silicon, with the last material to solidify (that bounding the $\mathrm{M}_{7} \mathrm{C}_{3}$ ) being depleted in chromium and enriched in silicon. The change in composition is significant between the first matrix to solidify and the matrix formed when there is just $9 \mathrm{wt}$ \% liquid remaining (at about $1200^{\circ} \mathrm{C}$ ), with the chromium level falling from $\sim 24$ at\% to $\sim 21$ at\% over this temperature range. It should be noted that these values cannot be directly compared with the values in Table 2 and Figure 12(b) since the carbon values are included in the data in Figure 13(b) but not included in the measured values. However, it should be noted that the highest predicted values of the chromium content of the matrix are around 24 at\%, whereas the measured values reported in Table 2 and Figure 12(b) are generally greater than 26 at. \%.

For the HIPed S-6, it is assumed that the equilibrium phase fractions and composition are achieved during the HIPing process which takes place at $1200^{\circ} \mathrm{C}$; moreover, due to relatively slow diffusion in the solid state on cooling from the HIPing temperature, the phase compositions and fractions in the material at room temperature are assumed to be those of predicted by equilibrium conditions at the HIPing temperature. Accordingly, Thermo-Calc was employed to predict the equilibrium composition and phase fractions at the HIPing temperature for the HIPed S-6 material, using the measured compositional information (as presented in Table 1). Under equilibrium conditions, the solidus temperature is just below $1260^{\circ} \mathrm{C}$, and at the HIPing temperature $\left(1200^{\circ} \mathrm{C}\right)$, the microstructure is made up of $11 \mathrm{wt} \% \mathrm{M}_{7} \mathrm{C}_{3}$ and $89 \mathrm{wt} \%$ Co-rich matrix. Table 4 shows the predicted compositions of the two phases at the HIPing temperature; it is noted that the predicted chromium content of the cobalt-rich matrix (24 at\%) 
is slightly less than the EDX-measured value of 25.2 at\% reported in Table 3, but that in general, there is good correlation between the predicted composition of the matrix (Table 4) and that measured by EDX analysis (Table 3). It is noted that the predicted chromium content in the matrix phase of the HIPed S-6 is similar to the highest matrix chromium content predicted for the cast S-6 (Figure 13b), but it is noted that the chromium content in the cast S6 is predicted to fall significantly as solidification proceeds.

\section{Discussion}

\section{Microstructural characteristics of the cast S-6 and HIPed S-6 alloys}

Although both materials examined in this work can be classified as S-6 alloys, there are a number of significant differences between the microstructures of the cast and the HIPed materials. In the cast S-6, a coarse microstructure is observed, with a dendritic matrix and $\mathrm{M}_{7} \mathrm{C}_{3}$ carbides in a semi-continuous network, with a small fraction of $\mathrm{M}_{12} \mathrm{C}$ carbides which decorate the boundaries between the $\mathrm{M}_{7} \mathrm{C}_{3}$ and the matrix. In the HIPed S-6, the $\mathrm{M}_{7} \mathrm{C}_{3}$ carbides are both much smaller and evenly dispersed and no $\mathrm{M}_{12} \mathrm{C}$ carbides are observed; in both cases, the experimental results are generally in accord with Thermo-Calc microstructural predictions The fine, evenly distributed carbide in the HIPed S-6 is typical of that of an alloy of this type produced from a gas-atomised powder [5]; during the solid state HIPing process, the carbides will grow only sluggishly due to the low diffusion rates, especially when compared to the growth of the carbides from the melt in the cast alloy.

The XRD patterns of the cast S-6 in Figure 4 and the HIPed S-6 in Figure 9 showed the same peaks but with very different intensities. The XRD pattern of the cast S-6 had peaks at $39^{\circ}, 44.8^{\circ}, 51.7^{\circ}$ and $82.8^{\circ}$ associated with $\mathrm{Cr}_{7} \mathrm{C}_{3}$ which exhibited higher intensities than the same $\mathrm{Cr}_{7} \mathrm{C}_{3}$ peaks in the XRD pattern of the HIPed S-6. The remaining Co fcc peaks had a higher intensity in the HIPed S-6 than in the cast S-6. In the cast S-6, each dendrite has one prevalent crystal orientation, and the coarse cast S-6 structure has therefore resulted in very 
different relative intensities of the various peaks when compared with the less textured HIPed S-6.

The measured chemical compositions of both the cast S-6 and HIPed S-6 are presented in Table 1; it is notable that the former contains higher amounts of carbon, iron and nickel (6.6, 3.0 and 2.6 at\% respectively for the cast alloy compared to $4.5,0.7$ and 0.8 at\% respectively for the HIPed alloy). The higher carbon content in the cast S-6 results in an increase in the carbide fraction (predicted to be $15 \mathrm{wt} . \%$ at the solidus temperature), which will result in more chromium (the strongest carbide former) being tied up in the carbides, and thus in its depletion from the matrix. In contrast, the significantly lower carbon content in the HIPed S-6 will result in a lower fraction of carbides (predicted to be 11 wt. \% at the HIPing temperature), but also in less chromium depletion from the matrix. However, it is recognised that the measured chromium contents of the cobalt-rich matrices in the two cases do not align with this prediction, with that in the cast S-6 being 26.3 at\% (Table 2) and that in the HIPed S-6 being 25.2 at\% (Table 3).

Table 1 indicates that there are some other significant differences in the basic compositions of the two alloys, the most notable being the iron content, with the cast S-6 and HIPed S-6 alloys having iron contents of 3.0 and 0.7 at\% respectively. A previous investigation by Crook [34] stated that iron may be detrimental to the corrosion resistance of cobalt-based alloys, and in this regard, the higher iron content and greater tendency for corrosion of the cast S-6 are noted.

\section{Corrosion behaviour of the cast S-6 and HIPed S-6 alloys}

The corrosion behaviour of the cast S-6 and HIPed S-6 alloys under the conditions examined are very different. Both show general corrosion as evidenced by the colouration following exposure; the interference colours observed indicate that the corrosion films are relatively thin (less than $~ 150 \mathrm{~nm}$ ) and thus indicate that both alloys exhibit high corrosion resistance. Similar behaviour was observed by Hocking and Lister [35] who investigated the corrosion of 
Stellite $6^{\circledR}$ in conditions simulating the primary circuit of an operating PWR and attributed this to the formation of a chromium-rich oxide over both the matrix and carbide phases.

It has been argued that HIPing results in enhanced in corrosion resistance due to reduced chemical segregation [36] and this is in accord with the observations presented in this paper. In contrast to the high levels of corrosion resistance observed for the HIPed S-6, the cast S-6 exhibited preferential corrosion of the Co-rich matrix close to the matrix-carbide boundary; this preferential corrosion was observed in the form of both a thicker corrosion film in this region (blueing as seen in Figure 5(d)) along with the formation of an oxide film between the carbide and the matrix (Figures 5(f) and 6(e)). It is proposed that there are two reasons why these types of corrosion are promoted, both of which depend upon the fact that the matrix close to the $\mathrm{M}_{7} \mathrm{C}_{3}$ is depleted in chromium due to segregation during solidification, with this being supported by both experimental evidence (Figure 12) and thermodynamic modelling (Figure 13(b)). Similar behaviour was seen in the corrosion of Stellite $6^{\circledR}$ weld-deposit in deaerated pH adjusted water which was attributed to chromium depletion in the matrix surrounding the carbides [37]. This chromium depletion in the matrix promotes: (i) general corrosion of the depleted matrix material (resulting in the blueing observed and formation of a dark boundary and a halo ); (ii) enhanced interfacial corrosion of the depleted material promoted by the high electrical potential between the matrix and the electrically conducting $\mathrm{M}_{7} \mathrm{C}_{3}$ carbide (as also observed in a Stellite 3 analogue alloy [20]) which results in the interfacial corrosion as seen in Figure 5(f). It is notable that in the work on the Stellite 3 analogue which was exposed under similar conditions to those employed in this work [20], the interfacial corrosion was seen to have a width of around $300 \mathrm{~nm}$ on the surface and penetrated to a depth of around $1 \mu \mathrm{m}$ below the surface. Moreover, although the Stellite 3 analogue had carbides of both $M_{7} C_{3}$ and $M_{12} C$ types (both of which are electrical conductors), corrosion was observed to occur only between the $\mathrm{M}_{7} \mathrm{C}_{3}$ and the matrix and not between the $\mathrm{M}_{12} \mathrm{C}$ and the matrix, with this difference being ascribed to the differences in electrical potentials; again, in the current work, in places where the grain boundary between the $\mathrm{M}_{7} \mathrm{C}_{3}$ and the matrix has been decorated with a film of silicon- 
rich $\mathrm{M}_{12} \mathrm{C}$ (Figure 5(f)), interfacial corrosion is not observed. For the exposed cast S-6 (Figure 7(d)), the highest current was measured in the Cr-rich carbide with a lower current being carried through the Co-rich matrix due to it being covered with a more insulating oxide corrosion product; the thicker oxide region with the blue colour (Figure 5(d) and 7(b)) had a high electrical resistance hence the lowest current was measured (Figure 7(d)).

Figure 3 indicates that whilst there is a small height difference between the carbide and matrix phase before autoclave exposure (due to preferential material removal in the grinding and polishing processes), this is much more pronounced following autoclave exposure, indicating that the general corrosive recession of the metallic matrix is faster than that of the carbides, with this observation in accord with the rest of the body of experimental evidence presented.

In contrast to the behaviour of the cast S-6, there is clear evidence that the HIPed S-6 does not exhibit preferential corrosion at the boundary between the Co-rich matrix and the Cr-rich carbide. Given that the carbide and matrix will be broadly similar to those in the cast S-6 (with similar electrical potentials between them), it is concluded that the matrix in the HIPed S-6 has a high enough chromium content to successfully resist interfacial corrosion. It is proposed that it is the chromium depletion in the matrix of the cast S-6 close to its interface with the Cr-rich carbide that results in preferential corrosion here; it is again noted that EDX measurements lacked the spatial resolution to adequately quantify the chromium depletion in the matrix close to the boundary with the Cr-rich carbide, and the measured values of $\sim 26$ at $\%$ are likely to be an overestimate due to signal emanating from the Cr-rich carbide itself. This is substantiated via the Scheil-Gulliver solidification modelling which indicates that the chromium content of the matrix solidifying at a particular temperature will have fallen to 21 at. \% even by $1200^{\circ} \mathrm{C}$.

Even where there is no chromium segregation in the matrix (such as is assumed to be the case in the HIPed S-6), the chromium concentration in the matrix (required to confer corrosion resistance) depends not only upon the overall chromium content, but also critically upon the carbon content of the alloy (with the carbon preferentially tying up the chromium in the form of carbides). For the HIPed S-6 alloy composition, Thermo-Calc was employed to make 
predictions of the effect of the overall carbon content of the alloy on both the equilibrium carbide content and on the equilibrium chromium content in the matrix at $1200^{\circ} \mathrm{C}$ (to simulate the HIPing conditions). As can be seen in Figure 14, the mass fraction of carbide increases with the carbon content (which will result in higher hardness, and potentially to higher wear resistance), but the chromium content of the matrix falls with increasing carbon level at a rate of approximately 7 at.\% $\mathrm{Cr}$ for each $1 \mathrm{wt} . \%$ carbon. As such, it is argued that care needs to be exercised with the alloy specification of S-6 alloys, as it is clear that over the allowed range of carbon contents $(0.9-1.4$ wt\%), there will be a significant difference in the chromium content of the matrix. The allowed range of the overall chromium content in the Stellite 6 specification ranges from $27-32 \mathrm{wt} \%$, and it is notable that the HIPed S-6 is towards the bottom of this range whilst the cast S-6 is in the middle of this range (Table 1). However, whilst the HIPed S-6 has an overall carbon content at the lower end of the allowed range (1.0 wt. $\%)$, the cast S-6 has a carbon content just above the upper end of the allowed range (1.5 wt. $\%$, and this combined with the significant chromium segregation in the matrix as a result of its solidification results in the localised corrosion observed in the cast S-6. It is suggested that in looking for S-6 alloys with high levels of corrosion resistance, then the chromium content should be towards the upper end of the range and the carbon content at the lower end of the range, especially when specifying a cast material where chromium segregation will take place during processing.

\section{Conclusion}

The corrosion behaviour of two commercially available Stellite 6 analogue materials in conditions designed to simulate conditions in a PWR primary circuit was examined. The two alloys differed both in their chemical composition but also (as a result of the different manufacturing methods) in their microstructures. Both alloys were made up of a Co-rich matrix and a Cr-rich carbide, with a small amount of W-rich carbide also in the cast alloy. Using a 
variety of techniques, it was demonstrated that in both alloys (cast S-6 and HIPed S-6), the Co-rich matrix corrodes more rapidly than the carbides, resulting in the formation of an electrically resistive oxide. In the HIPed S-6 alloy, the matrix is homogeneous in nature as the HIPing process will tend to promote equilibrium in the system, and this homogeneity means that no preferential corrosion of the matrix phase is observed in this material. In contrast, the cast S-6 exhibits significant segregation of chromium and silicon in the matrix phase, with chromium depletion close to the boundaries with the Cr-rich carbide. This segregation results in preferential corrosion of the matrix in these regions.

The corrosion behaviour has thus been shown to depend upon the inhomogeneities in the chromium content of the matrix, but it is also noted that it will depend not just upon the variation in the chromium content but also upon its absolute value. As well as casting giving rise to a microstructure which is more prone to corrosion, it is noted that high ratios of carbon to chromium (even within the allowed specifications for the alloy type) will lead to lower levels of chromium in the matrix, which will again make the alloy more prone to corrosion. In the alloys examined in this work, it is noted that the cast S-6 has a much higher carbon to chromium ratio that the HIPed S-6 alloy which may also have resulted in the corrosion behaviour observed.

\section{References}

1. GmbH, A.N., Primary Coolant Chemistry:Fundamental Aspects \& Improvements/Optimizations, A.N. GmbH, Editor. 2008, Areva NP GmbH: PaulGossen-Straße, Germany. p. 89.

2. Vikström, J., Galling resistance of hardfacing alloys replacing Stellite. Wear, 1994. 179(1): p. 143-146.

3. Yao, M. and R. Collier. Hardfacing Alloys and Processes for Advanced UltraSupercritical. Valve magazine.com 2016 05/07/2016 [cited 05/07/2016 02/01/2019]; Beyond Valves:[Available from: 
http://www.valvemagazine.com/magazine/sections/beyond-valves/7694-hardfacing-

\section{alloys-and-processes-for-advanced-ultra-supercritical.html.}

4. Davis, J.R. and A.S.M.I.H. Committee, Nickel, Cobalt, and Their Alloys, ed. J.R. Davis. 2000, Materials Park,Ohio,USA: ASM International. 422.

5. Zhang, X., Masters thesis on the investigation of corrosion behavior of wrought Stellite alloys, in Mechanical Engineering. 2012, Carleton University: Ottawa, Ontario, Canada. p. 23 of 170.

6. Bowden, D.J., PhD thesis on the assessment of cobalt-free hardfacing stainless steel alloys for nuclear applications., in School of materials, Faculty of Science and Engineering. 2016, University of Manchester: Manchester,UK. p. 29 of 256.

7. Loh, N.L. and K.Y. Sia, An overview of hot isostatic pressing. Journal of Materials Processing Technology, 1992. 30(1): p. 45-65.

8. N.Horton and R.Sheppard, Benefits of Tailoring Hot Isostatic Pressure/PowderedMetal (HIP/PM) and Additive Manufacturing (AM)To Fabricate Advanced Energy System Components, in 2016 NETL Crosscutting Research Review Meeting. 2016, Energy Industries of Ohio: Pittsburg, PA USA. p. 62.

9. D.Gandy, Innovative Manufacturing Process for Nuclear Power Plant Components via Powder Metallurgy \& Hot Isostatic Pressing Methods, D.Gandy, Editor. 2016, EPRI: USA. p. 36.

10. Meyer, H.T. and P. Crook. The Effects Of Microstructure (Cast versus Wrought) on the Wear and Corrosion Properties of a Cobalt-Based Alloy. in 12th international corrosion congress. 1993. Houston,Texas USA: NACE International.

11. Malayoglu, U. and A. Neville, Mo and $W$ as alloying elements in Co-based alloystheir effects on erosion-corrosion resistance. Wear, 2005. 259(1-6): p. 219-229.

12. Malayoglu, U., A. Neville, and H. Lovelock, Assessing the kinetics and mechanisms of corrosion of cast and HIPed Stellite 6 in aqueous saline environments. Corrosion Science, 2005. 47(8): p. 1911-1931. 
13. Placko, H.E., S.A. Brown, and J.H. Payer, Effects of microstructure on the corrosion behavior of CoCr porous coatings on orthopedic implants. Journal of Biomedical Materials Research, 1998. 39(2): p. 292-299.

14. K.E. Mohamed, et al., Localized Corrosion Behaviour of Powder Metallurgy Processed Cobalt-base Alloy Stellite-6 in Chloride Environments. Zeitschrift für Metallkunde, 1999. 90(3): p. 195-201.

15. Oldfield, J.W. and W.H. Sutton, New Technique for Predicting the Performance of Stainless Steels in Sea Water and other Chloride-containing Environments. British Corrosion Journal, 1980. 15(1): p. 31-34.

16. Malayoglu, U. and A. Neville, Comparing the performance of HIPed and Cast Stellite 6 alloy in liquid-solid slurries. Wear, 2003. 255(1): p. 181-194.

17. Wong-Kian, M., L.A. Cornish, and A. Van Bennekom, Comparison of erosion-corrosion behaviour of hot isostatically pressed and welded stellite coatings. Journal of the Southern African Institute of Mining and Metallurgy, 1995. 95(7): p. 319-334.

18. Neville, A. and U. Malayoglu, Aqueous Corrosion of Cobalt and its Alloys A2 - Cottis, Bob, in Shreir's Corrosion, M. Graham, et al., Editors. 2010, Elsevier: Oxford. p. 19161936.

19. Hocking, W.H., et al., Mechanisms of corrosion of stellite-6 in lithiated high temperature water. Corrosion Science, 1985. 25(7): p. 531-557.

20. Karimi, G.N., et al., Corrosion of cast Stellite-3 analogue in simulated PWR conditions. Corrosion Science, 2018. 140: p. 402-411.

21. Ahmed, R., et al., Influence of Re-HIPing on the structure-property relationships of cobalt-based alloys. Tribology International, 2013. 57: p. 8-21.

22. Andersson, J.O., et al., Thermo-Calc \& DICTRA, computational tools for materials science. Calphad, 2002. 26(2): p. 273-312.

23. Boettinger, W.J., The Solidification of Multicomponent Alloys. Journal of Phase Equilibria and Diffusion, 2016. 37(1): p. 4-18. 
24. Keller, T., et al., Application of finite element, phase-field, and CALPHAD-based methods to additive manufacturing of Ni-based superalloys. Acta Materialia, 2017. 139: p. 244-253.

25. Basak, C.B. and M. Krishnan, Applicability of Scheil-Gulliver solidification model in real alloy: a case study with Cu-9wt\%Ni-6wt\%Sn alloy. Philosophical Magazine Letters, 2015. 95(7): p. 376-383.

26. Glicksman, M.E. and R.N. Hills, Non-equilibrium segregation during alloy solidification. Philosophical Magazine A, 2001. 81(1): p. 153-159.

27. Lovelock, H.d.V., Background to stellite cobalt based alloys, H.d.V. Lovelock, Editor. 2005, Deloro Stellite: Swindon, United Kingdom. p. 1-10.

28. Rosalbino, F. and G. Scavino, Corrosion behaviour assessment of cast and HIPed Stellite 6 alloy in a chloride-containing environment. Electrochimica Acta, 2013. 111(Supplement C): p. 656-662.

29. Silence, W.L., Effect of Structure on Wear Resistance of Co-, Fe-, and Ni-Base Alloys. Journal of Lubrication Technology, 1978. 100(3): p. 428-435.

30. $\mathrm{Yu}, \mathrm{H}$., et al., Influence of Manufacturing Process and Alloying Element Content on the Tribomechanical Properties of Cobalt-Based Alloys. Journal of Tribology, 2008. 131(1): p. 011601-011601.

31. Somervuori, M., et al., Characterisation and corrosion of spot welds of austenitic stainless steels. Materials and Corrosion, 2004. 55(6): p. 421-436.

32. Guyard, C., et al., Solidification path and phase equilibria in the liquid-solid range of cobalt-base alloy. Journal of Materials Science, 1981. 16(3): p. 604-612.

33. Ghosh, A., Segregation in cast products. Sadhana, 2001. 26(1): p. 5-24.

34. Crook, P., The effects of dilution upon the corrosion and wear properties of cobaltbased weld overlays. Corrosion Science, 1993. 35(1): p. 647-653.

35. Hocking, W. and D. Lister, Corrosion of Stellite-6 in Lithiated and Borated Hightemperature Water. Surface and Interface Analysis, 1988. 11: p. 45-59. 
36. Georgette, F.S., Effect of hot isostatic pressing on the mechanical and corrosion properties of cast,porous coated Co-Cr-Mo alloy, in Quantitative Characterization and Performance of Porous Implants for Hard Tissue Applications:A symposium, J.E. Lemons, Editor. 1987, ASTM: Philadelphia,USA. p. 31-46.

37. LeClair, M.J., et al., Corrosion and Corrosion Product Release Behavior of Co-Cr-WC Weld Deposit, in Nace International corrosion conference \& expo 2015. 2015, NACE International. p. 1-15. 